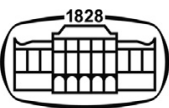

AKADÉMIAI KIADÓ

\title{
The health psychology approach to normal ageing
}

\author{
M. HOYER*
}

\section{Developments in Health Sciences}

$3(2020) 1,5-8$

DOI:

10.1556/2066.2020.00001

(c) 2020 The Author(s)

\section{REVIEW ARTICLE}

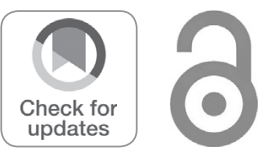

*Corresponding author. Department of Applied Psychology, Faculty of Health Sciences, Semmelweis University, Vas utca 17, Budapest, H-1088, Hungary. E-mail: maria.hoyer@vipmail.hu
Department of Applied Psychology, Faculty of Health Sciences, Semmelweis University, Budapest, Hungary

Received: July 04, 2018 • Revised manuscript received: November 10, 2018 • Accepted: September 02, 2019 Published online: August 7, 2020

\begin{abstract}
Approaching the process of normal ageing with a health psychology model was an important development in health science. In earlier healing models, questions of old age were either ignored or dealt with only in the context of various diseases. Definitions of the stages of human life have changed and pushed the limits of old age to a higher level. The expanding human life course raises important medical, psychological, and sociological issues. The definition of ageing and the characteristics of normal ageing need to be reconsidered. The cognitive representations of ageing people are a good reflection of how they think about themselves, the world, and the stage of life ahead. The contribution of health psychology as a modern approach to healthy ageing has greatly altered the attitudes of healthcare professionals. The concept of active old age helps to deal with the growing number of elderly people in a new context. In this brief overview of the health psychology approach to normal ageing, we aim to help healthcare professionals better manage the problems in their daily work. In a brief introduction, we review the physical and mental symptoms of ageing. We strive to isolate the normal variants from gerontopsychiatric and neuropsychiatric disorders. While normal ageing does not require clinical attention, psychiatric disorders do, and we briefly describe the therapeutic forms. Psychoeducation, group therapy, and supportive techniques prove to be the most effective.
\end{abstract}

\section{KEYWORDS}

normal ageing, health psychology, cognitive representations, active ageing, psychoeducation

\section{INTRODUCTION}

In the 1980s, the concept of health psychology was developed in the United States. It has brought two major innovations, which greatly contributed to the conception of ageing as not an illness. In addition to revealing the causes of chronic illnesses, it showed ageing as a natural process. The definition and medicalization of old age have previously resulted in the second half of life being the age of various illnesses, and death was a medical failure factor. Elderly people were subject to premature autopsy because their doctors were looking for the cause of death. Ageing was not considered a natural process, but a variant of disease or health.

The concept and conceptualization of health psychology have contributed to awareness the fact that ageing and the related changes are a natural part of life and not a disease. As the human body continues to evolve from conception and birth, it takes a reverse direction in the second half of life and gradually declines. What health professionals can do is follow the change of state and maintain the patient's health according to potentials and to what is available.

The WHO has defined the following life stages. 50-60 years of passage; 60-75 age of ageing; Age 75-90; Over 90; Above 100 Methuselah. It has also defined the notions of healthy ageing and related functional abilities and proposed that for healthy ageing people must be able to: Maintain basic needs, develop decision-making, stay mobile, maintain relationships and build them, and continue to contribute to the functioning of society.

Defining ageing is not easy, and there are several approaches. One is chronological and usually defines old age as over 65 . Another tries to define ageing along the lines of functions 
related to the general physiological state, the adaptive nature of the psychic condition, and the functioning of the social environment. A third approach defines ageing based on subjective judgement, i.e., how old someone feels. In addition, ageing is often defined as 1 . a process associated with "degrading" functional disorders or disease; 2. whereas "normal ageing" is a process in which the reduction in function is continuous but does not involve diseases or other pathological processes 3. and in "successful ageing," i.e., the physiological and psychosocial decline is small [1]. Healthy or normal ageing was first defined as a category in a WHO report [2] on active ageing. The change of attitude not only had health but also economic aspects. It does not matter whether the topic is an ageing society or an active old age because statistics predict that in 2050 every fifth person will be over 60 years old.

The health-psychological correlates of normal ageing can be easily captured by cognitive representations of health and illness. How people think about their symptoms and their illnesses, how they evaluate them, and how they relate to them play a major role in health-related behaviours, illnesses, and the healer-patient relationship. It is important to report what the diseases are related to. Health and illness symbol values vary greatly depending on social and cultural environments. Health can be a symbol of "good," "right" behaviour, a responsible and self-caring individual, while illness is the "bad" behaviour of people who do not care about themselves and is the basis of stigmatization, scapegoating, and exclusion.

Health education and prevention is an important part of shaping the process of normal and healthy ageing. Healthcare professionals should help patients understand the physical aspects of normal ageing and accept that they are part of a natural change. These physical aspects are discussed briefly below. Of the bodily symptoms, we are talking about the disruption of the emotions and the disturbances of the driving circle in general.

\section{AGEING-ASSOCIATED DISEASES}

\section{Sensory circle disorders}

Visual impairment may be the gradual and moderate depletion of visual acuity, and the fatigue of accommodation is an age-specific feature. Treatment of symptoms is mostly ophthalmic, but there may be neuropsychiatric aspects that are treated in complex neurological and psychiatric care [3]. Such visual disturbances include progressive visual impairment, sudden deterioration or loss of vision, vision defects, dual vision, and disturbing elemental or complex (optic illusion or hallucinations) visual acuity.

Hearing disorders are some of the most common symptoms of ageing, but hearing loss is not a general symptom, as it shows a great diversity. Most commonly, it is a problem when talking to a speaker in the context of social interaction for better understanding (automatic reading of the mouth). A more unpleasant symptom is tinnitus. The neuropsychiatric aspects of hearing disorders should also be considered. For example, tinnitus leads to behavioural abnormalities, as the constant whistling, rippling sound makes the elderly angry and may cause sleep disturbances. Acoustic hallucinations are uncommon, but if they occur, they may be signs of psychiatric illness. Whichever symptom is the first, it is important to check the connection between the two. Parosmia appears to some extent in any elderly person, but if daily activity is disturbed, the switch disruptions must be ruled out. Hypersensitivity and anosmia should be thought of as cerebral vascular processes and, in the case of anomalous hallucinations, epilepsy or other psychotic disorders may be suspected.

The biological basis of the loss of taste sensation is the diminishing number of taste buds. Instead of 240-250, there may be only 40-50. Flavours and the feelings associated with them may change considerably as age progresses. Not only does taste sensation change, but diet change, as a part of lifestyle change, means leaving the distinctive, strongly spicy flavours that can maintain a nostalgic desire. However, if old flavours are being tasted again, taste does not return, or the feelings of old flavours. In this stimulus mode, a taste sensation that appears as a symptom of psychosis may also arise.

Temperature sensation, skin senses of touch, and deep sensations are not part of the natural ageing process. At the same time, there may also be a reduction in vibration sensation and impairment of depth perception in elderly healthy people. This can affect movement on the stairs.

Numbness, feeling of needle piercing, and general symptoms associated with hypoesthesia, are caused by damage to peripheral nerves and percussion pathways. In the elderly, this is the most common sensory disorder since it is related to alcoholic, toxic, diabetic polyneuropathy. However, here may be iatrogenic harm, as well as the harm caused by medication. It is important to note that the explanation of the perceptions of the sentiment can only be interpreted in a complex biopsychosocial model. Therefore, it is very risky to use alternative or complementary medicine without thorough neuropsychiatric investigation. Furthermore, it is important to emphasize the health psychology approach to emotional disorders and the role of education and prevention.

Disturbances of the driving force are usually described in neuropsychiatric terms [3]. Here are some important points highlighted.

One of the consequences of normal ageing is a decrease in the weight and strength of the muscles by $30 \%$. This is the main reason why muscular anaerobic performance is reduced. The main forms of this are peripheral and central paresis, fatigue, reduced activity, walking disorder, awkwardness, trembling, shaking, involuntary movements, and holding problems.

From the health psychology point of view, we emphasize the role of regular movement and sport. For all disorders of the aged, whether somatic or mental, one of the most important antidotes is regular and enough movement. For the elderly, more and more programs are organized, the core of which is movement. These include lifestyle programs, 
leisure activities, excursions, sports, and exercise therapy, e.g., Tai chi.

The next topic is mental disorders affecting normal ageing. Like any symptoms associated with ageing, they are normal variants and can only be regarded as mental disorders if they reach the clinical level.

\section{Mental disorder symptoms}

Forgiveness: In tasks requiring rapid associativity, there is a decrease in fluid abilities, which is offset by a Christianized, wisdom-based component.

Mental decline: This includes memory decline and difficulty in understanding, or persevering. Attention is tyred and weakened. For this reason, it is suggested in the nurses' communication protocol to communicate with slow, wellarticulated, and easily understandable words.

Narrowing of initiative skill: There is no will to go anywhere, and past activities are narrowed. If movement diminishes along with interest, it will become more and more difficult to move the elderly out of their homes. While ageing does not necessarily coincide with sitting at home, it may increase age-related depression. From a health psychology perspective, prevention is a conscious preparation for ageing; it can help slow down the development of negative symptoms and the appearance of mental illness. The European Union's Horizon 2020 program focuses on active ageing, not just from the health conservation, but also the economic point of view [4]. To this end, numerous research projects have been launched to promote social activities and programs for active ageing, for example, learning to use a computer and the Internet. The projects bring different ages closer together, for example, through school programs, where young children can meet with older people who are impaired in their movement or speech or have other manifestations of ageing. The goal is that elderly people would not live in "reserves" but remain natural members of the communities.

Declining critical abilities: Older people can be victims of scams, let strangers inside, and buy everything. There may be a slight change in the critical sense as a sign of a more serious illness, such as Alzheimer's disease.

Confusion: Suddenly active employees find themselves in a new role as a passive pensioner. That is why it is important to prepare older people for life-cycle changes in advance - to create a continuity of experience in the field of utility. Sudden change is unfortunate. The rebound effect and changes in social roles in the aftermath of stress can cause diseases. This may be one of the reasons why many doctors get ill or die after retirement within a year.

Agitation and hetero aggression: Older people become grumpy, with a motor-driven urge and psychomotor unrest. The agitation is socially inadequate. It is a kind of repetitive verbal and motor behaviour, often involving aggression. In the background of neurotransmitters, serotonin has a regulatory role. In the regulation of aggressive behaviour, decreased 5-HT (serotonin), low noradrenaline, and high dopamine levels have been detected.
Failing sense of direction: Orientation weakens, mainly related to dementia. The more severe the dementia, the greater the disturbance of orientation in the field. If a client suffers disorientation in the home, it will increase during hospitalization. It is an important health psychology tenet that patients should not be "punished" for this by nurses but viewed as having a symptom of dementia and treated accordingly.

\section{Mood disorders}

Depressed, bitter mood: Mood is more susceptible to change in the elderly, and it may often turn negative. At the same time, it is important to note that the moodiness of normal ageing is not the same as clinical depression. Certain events experienced by the elderly in their earlier life may dramatically break into consciousness in the second half of life, due to changing memory functions. This is related to short-term memory degradation, typified by the "where did I put my glasses?" behaviour. This type of forgetting becomes more and more common while long-term memory is getting better. The latter is because $50-60$-year-old memories are accompanied by related emotions. Traumatic memories, unfortunately, surface, as well. Losses and sad stories can surface, along with their emotional intensity. One of my clients told me once that at the beginning of her retirement age she faced the negative memories of the past. She was a Holocaust survivor. She asked for help from a psychiatrist colleague, who said at the age of 70 nothing can be done except to cry together with the patient.

From a health psychology point of view, it is important that healthcare professionals reveal the meaningfulness of the lived life to our clients. This is a question of perspective, primarily. For example, the Holocaust-surviving old man, beyond the lamentation of losses, also should see posttraumatic growth [5] and be proud of it. The "What doesn't kill me, will make me stronger" principle or the "palm growing under the burden" can give a positive direction to these unexpectedly overwhelming memories and will not let the process go in the direction of depression. Unfortunately, psychiatrists are not well informed about the benefits of health psychology and spread their arms in the appearance of an elderly man in a desperate mood and respond with pharmacotherapy, which means the medicalization of the problem rather than an offer of humane help. Health psychology does not regard ageing as a disease, but a normal change. Following the principle of resilience, the second half of life is just coping with a task [6].

Common crying: In men, crying may be striking, as it contradicts the gender role of socialization, where men should be strong and not show emotion because it is a sign of weakness. However, in elderly people, and especially in males, frequent crying can be seen, suggesting that emotions are surfacing. Control of emotion changes, especially emotions related to memories that surface from the past or to death events in the present.

Mourning: Losing their contemporary people is more common in the elderly, so the mourning is even more prominent. The frequent crying was discussed above. The 
theory of health psychology and the positive psychology that develops from it should also be considered in this context. The inevitable fact of death in the earlier healing models could not be manifested because it meant an error factor. Even though "everyone dies, but no one is dead," according to the Tibetan Death Book. Modern health psychology and related positive psychology, in turn, bring death to the discursive space in order that it can be prepared for.

Suicidal thoughts: These thoughts come unexpectedly and can have serious consequences. Therefore, diagnostics in the elderly are important to exclude actual depression from just a bitter mood. It is also necessary to monitor the social situation of the elderly because there may be very prosaic reasons for suicidal thoughts.

Anxiety disorders and the side effects of antipsychotics are common in the elderly and often accompany a mood disorder. To become more manageable, the two should be differentiated. Anxiety conditions worsen afternoons and evenings. Sleeping difficulties and vegetative nerve activation are more common, less adaptive, and more dependent. While the depressed state is worse in the morning, it comes with a loss of energy and can cause problems with sleeping.

Emotional waves, mood swings, depression, and anxiety should be differentiated. Sometimes moodiness, manifests in increased activity, with compulsive and emphatic joking. This can be a burden to the social environment and may cause negative reactions.

\section{Content disturbances of thought}

Suspicious behaviour: The elderly person may become the "child" of a dominant parent and need to be supervised, even in the most fundamental aspects of sustainment. This will be processed through a self-protecting mechanism.

Delusions of theft or persecution: There may be accusations such as: "Stealing of all my belongings," "their house is not their own home," "impostor relatives," "abandonment," "infidelity, cheating," etc. These delusions have to be verified because they may have a basis in some cases.

Hypochondria complaints: Convulsions are common, but they may be unusual in character. The reasons for this have been discussed above, in the changed perception section. Sensory sensations can not only change in the sense organs, but impulses may increase in the direction of the visceral organs.

\section{THERAPIES}

The health psychology approach to normal ageing also contributes to the choice of appropriate therapeutic forms. The best "therapy" is prevention, the most important form of psychoeducation. The role of educational lectures has increased recently. This is referred to by the Budapest Retired Academy and similar educational forms. Another important development in therapies is the wide range of group therapies. Bibliotherapy, which maintains memory functions, can channel verbal expression and emotion control. Art therapy has proven to be effective in people with Alzheimer's disease. The role of motion therapy has already been described above. Working with ageing people requires increased empathy and supportive attitudes. Supportive therapy is recommended for psychotherapy. Finally, drug therapies can also provide an effective way to optimize the health of the elderly.

\section{DISCUSSION}

According to WHO data, in 2050 every fifth person will be over 60 years old. This is a challenge for healthcare professionals. With the right approach, health psychology can transform the lives of people over the age of 60 with the concept of active ageing. The natural state of change is not an illness. Education is important. This brief overview has provided a starting point for those interested in using the concepts of health psychology to address the problem of ageing with a state-of-the-art approach.

Conflict of interest/Funding: The authors declare no conflict of interest and no financial support was received for this study.

\section{REFERENCES}

1. Bárdos Gy. Az élet árnyoldalai - fájdalom, öregedés, halál. (Viselkedés élettan 2.) [Downsides of life - pain, aging, death. (Behavioural physiology 2.)]. Budapest: Scolar Kiadó; 2006.

2. WHO. Active ageing: a policy framework [Internet]. Switzerland: World Health Organization, Noncommunicable Disease Prevention and Health Promotion, Ageing and Life Course; 2002 [cited 2018 Nov 10]. Available from: https://apps.who.int/iris/bitstream/handle/ 10665/67215/WHO_NMH_NPH_02.8.pdf;jsessionid=8E43459398 890E934D9631BED549A774? sequence $=1$.

3. Rajna P, Tariska P. Az időskor neuropszichiátriája. [Neuropsychiatry of ageing]. Budapest: B+V Lap- és Könyvkiadó Kft; 2000.

4. Horizon 2020 [Internet]. European Commission; [cited 2018 Nov 10]. Available from: https://ec.europa.eu/programmes/horizon2020/.

5. Kulcsár Zs, editor. Teher alatt. . .Pozitív pszichológia és poszttraumás személyiségfejlödés. [Under burden... Positive psychology and posttraumatic growth as personality development]. Budapest: Trefort Kiadó; 2005.

6. Zautra AJ, Hall JS, Murray KE. Resilience: a new definition of health for people and communities. In: Reich JW, Zautra AJ, Hall JS, editors. Handbook of adult resilience. New York, NY: The Guilford Press; 2010. pp. 3-30.

\footnotetext{
Open Access statement. This is an open-access article distributed under the terms of the Creative Commons Attribution 4.0 International License (https:// creativecommons.org/licenses/by/4.0/), which permits unrestricted use, distribution, and reproduction in any medium, provided the original author and source are credited, a link to the CC License is provided, and changes - if any - are indicated. (SID_1)
} 